\title{
Axonal Transport of Human Immunodeficiency Virus Type 1 Envelope Protein Glycoprotein 120 Is Found in Association with Neuronal Apoptosis
}

\author{
Alessia Bachis, ${ }^{1}$ Sadia A. Aden, ${ }^{1}$ Rachel L. Nosheny, ${ }^{1}$ Peter M. Andrews, ${ }^{2}$ and Italo Mocchetti ${ }^{1}$ \\ Departments of ${ }^{1}$ Neuroscience and ${ }^{2}$ Cell Biology, Georgetown University Medical Center, Washington, DC 20057
}

\begin{abstract}
Patients infected by human immunodeficiency virus type 1 (HIV-1) develop acquired immune deficiency syndrome-associated dementia complex (ADC), a disorder characterized by a broad spectrum of motor impairments and cognitive deficits. The number of cells in the brain that are productively infected by HIV-1 is relatively small and consists predominantly of macrophages and microglia, yet HIV-1 causes widespread neuronal loss. A better understanding of the pathogenic mechanisms mediating HIV-1 neurotoxicity is crucial for developing effective neuroprotective therapies against ADC. The HIV-1 envelope glycoprotein 120 (gp120), which is shed from the virus, is one of the agents causing neuronal cell death. However, the cellular mechanisms underlying its neurotoxic effect remain unclear. We report that gp 120 injected into the rat striatum or hippocampus is sequestered by neurons and subsequently retrogradely transported to distal neurons that project to these brain areas. Cleaved caspase-3 and terminal deoxynucleotidyl transferase-mediated biotinylated UTP nick end labeling, hallmarks of apoptosis, were seen in neurons internalizing and transporting gp120. The retrograde transport of gp120 and apoptosis were mediated by the chemokine receptor CXCR4 because AMD3100, a selective CXCR4 inhibitor, blocked both events. Furthermore, colchicine or nocodazole, two inhibitors of intracellular trafficking, abolished gp120-mediated apoptosis in distal areas. These results indicate that axonal transport of gp120 might play a role in HIV-1-mediated widespread neuronal cell death.
\end{abstract}

Key words: basal ganglia; cerebral cortex; CXCR4; hippocampus; neurodegeneration; AIDS dementia complex

\section{Introduction}

Acquired immune deficiency syndrome-associated dementia complex (ADC) is frequent in human immunodeficiency virus (HIV)-positive patients in the late phase of infection and is characterized by neuronal cell death and neurological symptoms (Price, 1996; Masliah et al., 1997). HIV-infected cells consist almost exclusively of perivascular macrophages and microglia (Lee et al., 1993; Persidsky and Gendelman, 2003), and viral load does not always correlate with the clinical manifestation of the disease (Kure et al., 1991). Thus, an intriguing and yet unresolved issue in the neuropathogenesis of HIV is how relatively few infected cells can produce pronounced neuronal dysfunction and cause widespread neuronal atrophy.

HIV-1 infects macrophages and lymphocytes after binding of the envelope glycoprotein 120 (gp120) to several chemokine receptors in conjunction with CD4 (Berger et al., 1999). M-tropic HIV-1 strains use CC-chemokine receptor 5 (CCR5), whereas T-tropic strains use CXC-chemokine receptor 4 (CXCR4). CCR5-using viruses predominate in the initial stage of infection,

\footnotetext{
Received Aug. 30, 2005; revised May 10, 2006; accepted May 13, 2006.

This work was supported by National Institutes of Health Grants NS040670, NS047977, and NS046234. We thank Drs. D. Ginty and E. O. Major for insightful discussion.

Correspondence should be addressed to Dr. Italo Mocchetti, Department of Neuroscience, Georgetown University, Research Building, Room EP04, Box 571464, 3970 Reservoir Road NW, Washington, DC 20057. E-mail: moccheti@georgetown.edu.

DOI:10.1523/JNEUROSCI.1054-06.2006

Copyright $\odot 2006$ Society for Neuroscience $\quad 0270-6474 / 06 / 266771-10 \$ 15.00 / 0$
}

whereas a switch from CCR5- to CXCR4-using viruses occurs in the late stages of infection in a subset of patients (for review, see Everall et al., 2005). In the brain, expression of CCR5 (Ghorpade et al., 1998; Albright et al., 1999; Klein et al., 1999) occurs predominantly in microglia. CXCR4, initially identified as the receptor for stromal cell-derived factor $1 \alpha$ (SDF or CXCL12), is a member of the G-protein-coupled receptor superfamily (for review, see Rossi and Zlotnik, 2000) widely expressed in the CNS in glial cells and neurons (Lavi et al., 1997; Hesselgesser and Horuk, 1999; van der Meer et al., 2000). CXCR4 has multiple functions. It participates in neuronal injury and inflammation (Stumm et al., 2002), as well as in the migration of neuronal progenitors (Ma et al., 1998; Zou et al., 1998; Bagri et al., 2002; Lazarini et al., 2003). Intriguingly, CXCR4 binds to gp120 T-tropic strains (Deng et al., 1996; Tarasova et al., 1998) and causes neurotoxicity even in the absence of CD4 (Meucci et al., 1998; Klein et al., 1999; Zheng et al., 1999; Biard-Piechaczyk et al., 2000; Bezzi et al., 2001). Moreover, SDF, which is present at high levels in the brain of HIVinfected individuals, induces neuronal apoptosis in rodent brain (Zhang et al., 2003) as well as in vitro (Hesselgesser et al., 1998; Zheng et al., 1999; Bachis and Mocchetti, 2004). Similarly, overexpression of gp120 in transgenic mice (Toggas et al., 1994) or intracerebroventricular infusion of this glycoprotein in rat brain (Bagetta et al., 1996; Bansal et al., 2000; Maccarrone et al., 2000; Acquas et al., 2004) promotes degeneration of neurons, loss of dendritic markers, ventricular enlargement, and other severe neuronal abnormalities that are commonly seen in ADC patients. 
These data suggest that T-tropic strains that appear late in the course of infection might cause neuronal apoptosis and dementia. However, how the interaction between gp120 and CXCR4 that occurs at the cellular surface leads to neuronal cell death remains to be established.

In vitro gp120 induces neuronal damage only when internalized and transported to neuronal soma (Bachis et al., 2003), suggesting that in vivo the internalized envelope protein may travel along axons to distal neurons. This cellular mechanism, if proven, will give insight into the mechanism by which T-tropic HIV-1 causes cognitive impairment and neuronal loss without infecting neurons. Thus, in this study, we investigated the hypothesis that neuronal internalization and transport of gp120 is crucial for its neurotoxic effect.

\section{Materials and Methods}

Animal treatment. All surgical procedures were performed in strict accordance with the Laboratory Animal Welfare Act, with National Institutes of Health Guide for the Care and Use of Laboratory Animals, and after approval from the Georgetown University Animal Care and Use Committee. Details of injection procedures have been described previously (Nosheny et al., 2004). Coordinates for injecting gp120 strain IIIB (Immunodiagnostics, Woburn, MA) or other compounds into the striatum [anteroposterior (AP), $+0.7 \mathrm{~mm}$; mediolateral (ML), $\pm 3.0 \mathrm{~mm}$; dorsoventral (DV), $-6.0 \mathrm{~mm}$ from bregma], hippocampus (AP, $-3.8 \mathrm{~mm}$; $\mathrm{ML}, \pm 3.8 \mathrm{~mm}$; DV,$-3.8 \mathrm{~mm}$ from bregma), or fimbria (AP, $-3.8 \mathrm{~mm}$; $\mathrm{ML}, \pm 4.6 \mathrm{~mm}$; DV,$-5.2 \mathrm{~mm}$ from bregma) were according to Paxinos and Watson (1998). Compounds were delivered by a microperfusion pump $(0.2 \mu \mathrm{l} / \mathrm{min}$ for $15 \mathrm{~min})$. After completion of each injection, the needle was left in place for an additional $4 \mathrm{~min}$ to accomplish quantitative diffusion of the volume delivered. Animals were then returned to their cages. At the appropriate survival times, animals were deeply anesthetized with ketamine/xylazine ( 80 and $10 \mathrm{mg} / \mathrm{kg}$, i.p., respectively), followed by intracardiac perfusion of $4 \%$ paraformaldehyde in $0.1 \mathrm{~m} \mathrm{PBS}$, $\mathrm{pH} 7.4$, for immunohistochemical analyses.

Immunohistochemical analyses. For gp120 and cellular markers, brain sections $(16 \mu \mathrm{m})$ were incubated overnight at $4^{\circ} \mathrm{C}$ with a gp120IIIBspecific antibody (1:200; Immunodiagnostics) and either microtubule associated protein-2 (MAP2) or neuronal-specific nuclear protein (NeuN) (1:250 and 1:500, respectively; Chemicon, Temecula, CA) to visualize neurons, or CD68 (1:500; Serotec, Raleigh, NC) or glia fibrillary acidic protein (GFAP) (1:200; Chemicon) to visualize microglia or astrocytes, respectively. Sections were then incubated with Alexa-Fluor 488 (1:2000; Invitrogen, Carlsbad, CA) and Alexa-Fluor 594 secondary antibodies (1:2000; Invitrogen) to visualize gp120 and cellular markers, respectively.

For gp120 and CXCR4, sections were incubated overnight with an antibody against gp120IIIB along with a specific CXCR4 antibody (1:50; Chemicon). Sections were then incubated with Alexa-Fluor 488 and Alexa-Fluor 594 secondary antibodies to visualize gp120 and CXCR4. For tyrosine hydroxylase (TH) and gp120, sections were incubated with an anti-TH antibody (1:200; Chemicon) for $48 \mathrm{~h}$ and then overnight with gp120IIIB antibody. Sections were then incubated with Alexa-Fluor 594 and Alexa-Fluor 488 secondary antibodies to visualize TH and gp120, respectively.

For caspase- 3 and gp 120, after incubation with 5\% normal goat serum, sections were incubated with a cleaved caspase- 3 antibody (1:150 dilution; Cell Signaling Technology, Beverly, MA) for $48 \mathrm{~h}$ at $4^{\circ} \mathrm{C}$. Sections were then incubated overnight with gp120IIIB antibody. After three washes, sections were incubated with Alexa-Fluor 488 and Alexa-Fluor 594 secondary antibodies to visualize gp120 and caspase-3, respectively. For in situ terminal deoxynucleotidyl transferase-mediated biotinylated UTP nick end labeling (TUNEL) and gp120, sections were incubated with gp120 antibody overnight at $4^{\circ} \mathrm{C}$, and then TUNEL was performed as described previously (Bachis et al., 2003; Acquas et al., 2004). All sections were then mounted using Vectashield mounting medium (Vector Laboratories, Burlingame, CA).
Histological analysis. Sections were analyzed with a Zeiss (Thornwood, NY) fluorescence microscope Axioplan2. Positive cells were counted using a $20 \times$ objective and MetaMorph Imaging software (Universal Imaging Corporation, Downingtown, PA). The number of gp120- and/or caspase-3-positive cells in the striatum was assessed in an area of 250 $\mu \mathrm{m}^{2}$ in each section after excluding the sections with the needle tract $(\sim 40 \mu \mathrm{m})$. The entire striatum was analyzed. Similarly, positive cells in the hippocampus were counted in an area of $150 \mu \mathrm{m}^{2}$, up to $160 \mu \mathrm{m}$ rostral and $160 \mu \mathrm{m}$ caudal to the injection site. In the substantia nigra (SN) and septum, positive cells were counted along the entire length of these areas. Cells were counted only based on staining, not shape, size, or other measurable quantities.

Cerebellar granule cells. Cerebellar granule cells (CGCs) were prepared from 8-d-old Sprague Dawley rat pups (Taconic Farms, Germantown, NY) as described previously (Brandoli et al., 1998; Bachis et al., 2003). Briefly, CGCs were grown on glass coverslips in Basal Medium Eagle (Invitrogen) containing glutamine (2 mM), fetal calf serum $(10 \%), \mathrm{KCl}$ $(25 \mathrm{~mm})$, gentamicin $(100 \mu \mathrm{g} / \mathrm{ml})$, and penicillin-streptomycin $(10,000$ $\mathrm{U} / \mathrm{ml})$. Cytosine arabinoside $(10 \mu \mathrm{M})$ was added $24 \mathrm{~h}$ after cell plating to inhibit glial proliferation. At the time of the experiments, these cultures were composed of $\sim 96 \%$ neurons and $\sim 4 \%$ non-neuronal cells, such as astrocytes, oligodendrocytes, and endothelial cells. Compounds were added at $8 \mathrm{~d}$ in vitro.

For immunocytochemistry, cells were fixed with $4 \%$ paraformaldehyde and incubated with antibodies against MAP2 and gp120 overnight at $4^{\circ} \mathrm{C}$. Cells were washed and then incubated with Alexa-Fluor 488 and Alexa-Fluor 594 secondary antibodies to visualize gp120 and MAP2, respectively. To detect activated caspase-3, neurons were fixed and incubated with a cleaved caspase-3 antibody (1:500; Cell Signaling Technology), followed by Alexa-Fluor 488 secondary antibody. Coverslips were then mounted using Vectashield mounting medium containing $4^{\prime}, 6^{\prime}$ diamidino-2-phenylindole (DAPI). Immunofluorescence was analyzed with Axioplan2. Positive cells were counted using a $20 \times$ objective and MetaMorph Imaging software.

Electron microscopy. CGCs were exposed to gp120 HIV-1 IIIB conjugated to colloidal gold ( $25 \mathrm{~nm}$ mean particle size; Immunodiagnostics). Neurons were fixed by the addition of $4 \%$ phosphate-buffered glutaraldehyde directly to an equal amount of culture media. After overnight immersion fixation at room temperature, neurons were removed from the culture wells by scrapping and transferred to conical centrifuge tubes. The glutaraldehyde-fixed CGCs were rinsed in phosphate buffer and postfixed for $45 \mathrm{~min}$ in $1 \%$ phosphate-buffered osmium tetroxide. The postfixed cells were rinsed in water, stained en bloc in $2 \%$ uranyl acetate for $2 \mathrm{~h}$ (in the dark), dehydrated through graded acetones, and embedded in Spur low viscosity embedding medium (Polysciences, Warrington, $\mathrm{PA}$ ). Thin sections $(40-60 \mathrm{~nm})$ were cut using a diamond knife (Daitome, Biel, Switzerland) mounted on a Powertome XL ultramicrotome (Boeckeler Instruments, Tucson, AZ). The ultrathin sections were mounted on nickel grids and examined and photographed using a Hitachi (Pleasanton, CA) model 7600 transmission electron microscope operating at $80 \mathrm{kV}$.

Statistical analysis. Data were evaluated by ANOVA with post hoc Holm-Sidak test (SigmaStat software; Systat Software, Point Richard, CA).

\section{Results}

\section{gp120 is internalized by neurons}

To determine whether gp120 is internalized in vivo, adult male rats received an acute injection of vehicle control comprising heat-inactivated gp120 in $0.1 \%$ bovine serum albumin (BSA) (referred to as VEH throughout this study) or 400 ng of gp120 (strain IIIB) in $0.1 \%$ BSA into the striatum (Fig. 1a) as described previously (Nosheny et al., 2004). This concentration of gp120 was used because it causes a confined neuronal apoptosis without eliciting neurological impairments (Nosheny et al., 2004). Rats were then killed $24 \mathrm{~h}$ after the injection. Serial sections from the striatum were double stained with an antibody against gp120IIIB and NeuN, a specific neuronal marker, GFAP, a marker for as- 

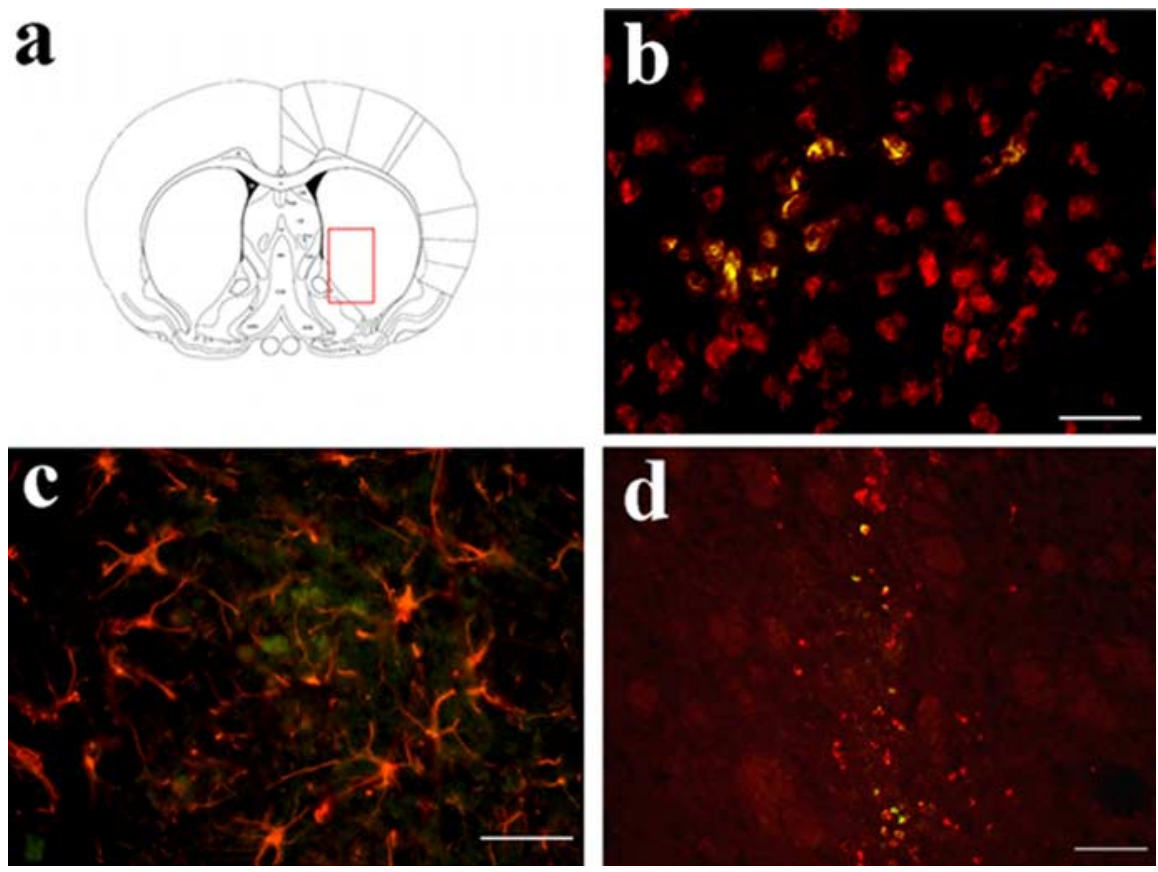

Figure 1. Neuronal internalization of gp120. $\boldsymbol{a}$, VEH or gp120IIIB was injected into the striatum (see boxed area) as described previously (Nosheny et al., 2004). Animals were killed $24 \mathrm{~h}$ later. gp120-IR was examined by immunohistochemistry in serial sections from the striatum. $\boldsymbol{b}-\boldsymbol{d}$, Higher magnifications of boxed area in $\boldsymbol{a}$. Sections were stained with a gp 120 antibody (green), followed by NeuN ( $\boldsymbol{b}$, red), GFAP ( $\boldsymbol{c}$, red), or CD68 (d, red). Yellow is green plus red. Note that gp120-IR in $\boldsymbol{d}$ follows the needle track. Scale bar, $100 \mu \mathrm{m}$.

trocytes, or CD68, a marker for microglia. VEH-treated rats showed no evidence of gp120 immunoreactivity (IR), supporting previous findings that boiling gp120 inactivates its activity as well as its antigenicity (Bachis et al., 2003). In gp120-treated rats, gp120-IR was confined in an area of $\sim 250 \mu \mathrm{m}^{2}$ in several sections of the striatum. The majority $(\sim 98 \%)$ of gp120-positive cells exhibited colocalization with NeuN (Fig. 1b), whereas none of the GFAP-positive cells were also gp120 positive (Fig. 1c). A small fraction of microglia cells $(\sim 2 \%)$ were gp120 positive (Fig. $1 d)$, but, unlike neurons, these cells were localized along the needle tract. Thus, it is likely that inflammatory and/or mechanical events triggered by the needle may aid gp120 entry into nonneuronal cells.

\section{Neuronal internalization of gp120 is mediated by CXCR4}

The strain of gp120 (IIIB) used in the present study binds to CXCR4. Most of our knowledge concerning the mechanism of gp120 internalization originates from in vitro evidence obtained in non-neuronal cells expressing CXCR4 (Tarasova et al., 1998; Orsini et al., 2000). Therefore, to initially define the role of neuronal CXCR4 in the internalization process, we examined whether neurons accumulating gp120 were also CXCR4 positive. Sections from the striatum were double stained for gp120 and CXCR4. A distinct immunostaining pattern of gp120-IR was observed around CXCR4-positive cells and was characterized by a diffuse fine-granular distribution resembling presynaptic boutons (Fig. 2a). Although both GFAP- and NeuN-positive cells expressed CXCR4, only neurons were positive for both gp 120 and CXCR4 (Fig. 2b), supporting previous in vitro data that gp120 internalization occurs only in neurons and requires CXCR4 (Bachis et al., 2003).

To provide evidence that the CXCR4-mediated internalization process plays a crucial role in gp120 neurotoxicity, rats re- ported after internalization.

ceived gp120 (400 ng) in the striatum alone or in combination with AMD3100 ( $1 \mu \mathrm{g}$ in $0.1 \% \mathrm{BSA}$ ). AMD3100 is a selective antagonist of CXCR4 (Donzella et al., 1998) that has been shown to inhibit gp120IIIB toxicity (Bezzi et al., 2001). Animals were killed $4 \mathrm{~d}$ later, and brain sections from the rostrocaudal extension of the striatum were stained with gp120 and activated caspase- 3 antibodies. Caspase- 3 is a proapoptotic protease that has been shown to be crucial for gp120 toxicity in neurons (Garden et al., 2002; Bachis et al. 2003). AMD3100 inhibited gp120 accumulation in striatal neurons (Fig. $2 c$ ), as well as the activation of neuronal caspase-3 (Fig. 2d), further indicating that binding to CXCR4 and internalization of gp120 are key events implicated in its neurotoxic effect.

\section{gp120 is transported to distal neurons}

The role of CXCR4 in neuronal maturation has been established (Klein et al., 2001). Our discovery that CXCR4 mediates gp120 internalization into neurons and consequently apoptosis adds a new concept in the neurobiology of this receptor. Nevertheless, it is crucial to demonstrate whether gp120 is axonally trans-

To determine whether gp120, once internalized, is retrogradely transported from synaptic terminals to cell bodies, gp 120 was injected into the striatum, and gp120-IR was examined in neurons of the SN pars compacta, which gives rise to one of the major afferent projections to the striatum. Dopaminergic neurons and fibers of the SN were visualized by an antibody against $\mathrm{TH}$ (Fig. $3 a$ ), the rate limiting enzyme for dopamine synthesis. To provide a temporal profile of gp120 transport, animals were killed at different time points 1, 2, 4, 7, and $15 \mathrm{~d}$ after the injection. gp120-IR was undetectable in the $\mathrm{SN}$ in control rats at any time (data not shown) or by $1 \mathrm{~d}$ in gp 120 -treated rats (Fig. 3e). In these animals, by $48 \mathrm{~h}$, only few gp120-positive cells were detected in the SN (Fig. 3e). However, by $4 \mathrm{~d}$ (Fig. $3 a, b$ ) and up to $15 \mathrm{~d}$ (Fig. 3e), several TH-positive cells in the SN pars compacta were also gp120 positive. No gp120-IR was observed around the lateral ventricle or in areas adjacent to the striatum such as the corpus callosum and basal forebrain (data not shown), suggesting that gp120-IR seen in the $\mathrm{SN}$ is attributable to active transport and not to diffusion.

The cerebral cortex is another major source of projections to the striatum. In particular, pyramidal glutamatergic neurons in layer $\mathrm{V}$ provide the main cortical projections, with additional input coming from layers III and VI. Therefore, a portion of gp120 injected in the striatum could be retrogradely transported to the cerebral cortex. To determine whether gp120 axonal transport is specific only to the nigrostriatal system, sections throughout the cerebral cortex were stained for gp120 and neurofilament. A number of neurofilament-positive cells were also positive for gp120 (Fig. 3c-e). Most gp120-IR was localized in the somatosensory cortex in neurons of layer 5 (Fig. $3 c, d$ ). These results indicate that retrograde axonal retrograde transport is a common way by which gp120 can reach distal brain areas and help explain 


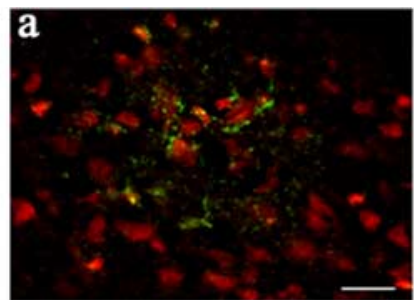

c

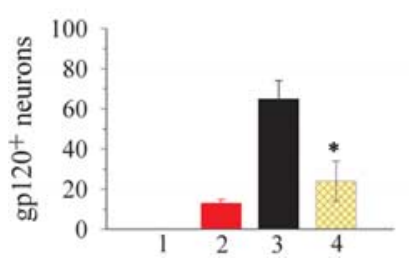

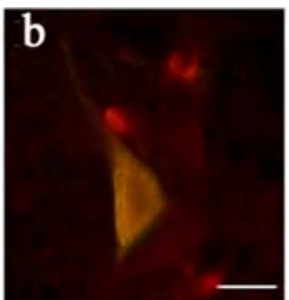

d

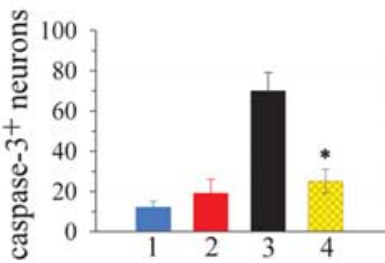

Figure 2. AMD3100 reduces apoptosis. Rats received VEH (1), AMD3100 (2), gp120 alone (3) or in combination with AMD3100 (4) into the striatum and were killed $24 \mathrm{~h}(\boldsymbol{a}, \boldsymbol{b})$ or $4 \mathrm{~d}(\boldsymbol{c}, \boldsymbol{d})$ later. $\boldsymbol{a}, \boldsymbol{b}$, Representative striatal sections of rats treated with gp 120 incubated overnight with an antibody against gp 120 (green) along with a specific CXCR4 antibody (red). Yellow is red plus green. Scale bars: $\boldsymbol{a}, 30 \mu \mathrm{m} ; \boldsymbol{b}, 50 \mu \mathrm{m}$. The number of cells positive for gp120-IR (c) and caspase-3-IR (d) were counted in sections throughout the striatum in an area $250 \mu \mathrm{m}^{2}$. Data, expressed as the mean \pm SEM of four animals (at least 10 sections both caudal and rostral to the injection site per animal), represent the average number of positive cells per section. ${ }^{*} p<0.01$ versus gp120.

the spread of neurodegeneration seen in ADC despite the poor correlation between viral load and neuronal atrophy in these individuals (Kure et al., 1991).

\section{Retrograde transport of gp120 occurs in different neuronal populations}

To determine whether retrograde transport of gp120 occurs in other neuronal subtypes, rats were injected with VEH or gp 120 in the dorsal hippocampus and were killed 1 and $4 \mathrm{~d}$ after the injection. Serial sections throughout the hippocampus were analyzed for gp120-IR. Double stainings with NeuN or GFAP were also performed. In control rats, no gp120-IR was observed. In gp120treated rats, several neurons in the CA3 region exhibited gp120-IR (Fig. $4 a$ ) by 24 h, suggesting that gp120 may diffuse from the injection site to the adjacent CA3 region. No GFAPpositive cells were also gp120 positive by $24 \mathrm{~h}$ (Fig. $4 b$ ) and $4 \mathrm{~d}$ (data not shown). The majority of gp120-positive neurons were also CXCR4 positive (Fig. 4c), confirming that this receptor may play a crucial role in gp120 internalization. No gp120-IR was observed in the contralateral hippocampus (Fig. $4 g$ ) by $24 \mathrm{~h}$. However, by $4 \mathrm{~d}$, several MAP2-positive cells, indicative of neurons, were positive for gp120 in the contralateral hippocampus (Fig. $4 d, g$ ). The envelope protein was localized not only in the cell bodies but also in neuronal processes (Fig. $4 d$, arrows), strongly indicating a neuronal transport of gp 120.

To further examine axonal transport of gp120, we took advantage of the ability of the septohippocampal pathway to transport proteins from the target area, the hippocampus, to the basal forebrain. Rats received an injection of gp120 in the fimbria and were killed at various times after the injection. By 4 d, gp120-IR was found in NeuN-positive cells of the septum, mainly in the medial septal nucleus (Fig. 4e) and the nucleus of the diagonal band of Broca (Fig. 4f). Accumulation of gp120 into septal neurons and contralateral hippocampus continued at least up to $15 \mathrm{~d}$ after the injection (Fig. 4g). These data further indicate that gp120 is ac-

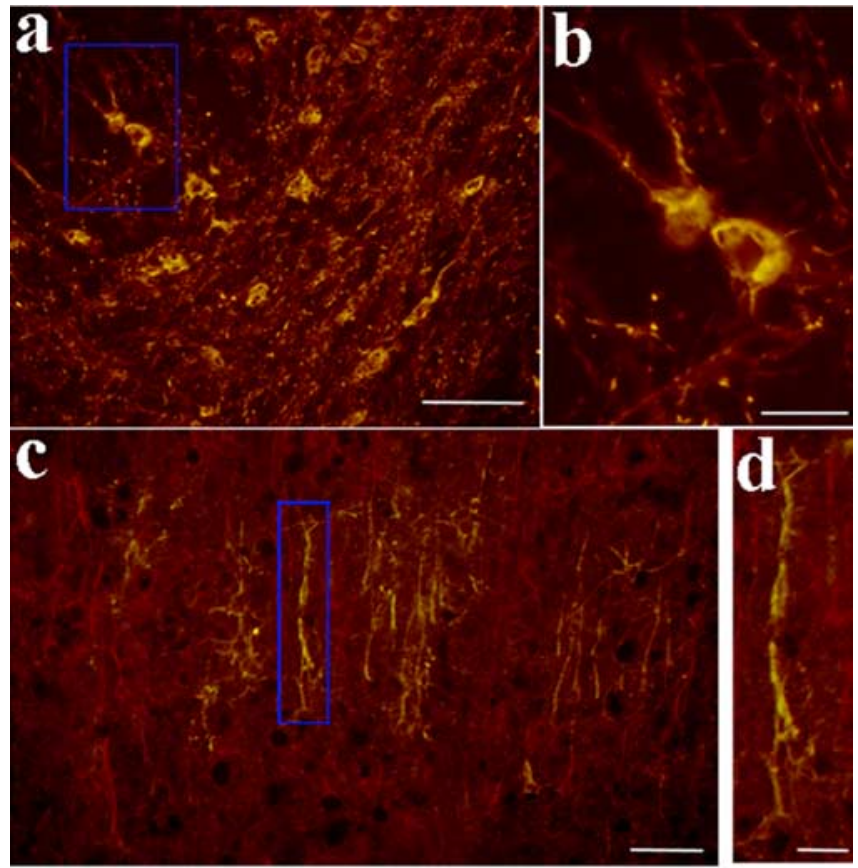

$\mathbf{e}$

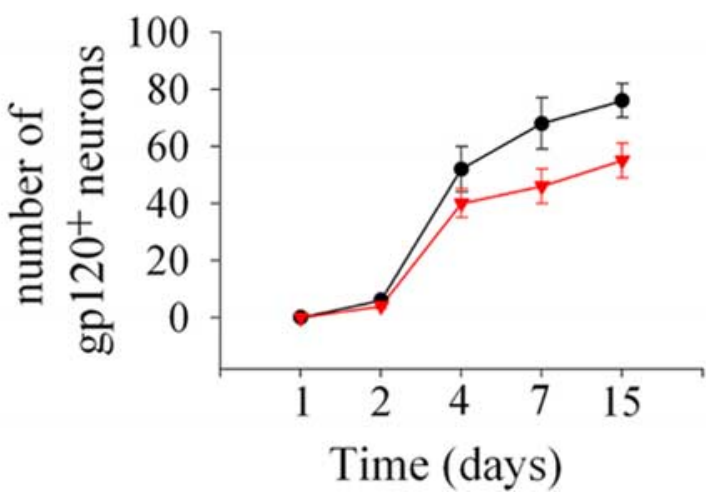

Figure 3. Retrograde axonal transport of gp120. Rats received gp120 into the striatum and were killed at different days after the injection. $\boldsymbol{a}, \boldsymbol{b}$, Representative sections from the SN of gp120-treated rats (killed $4 \mathrm{~d}$ after the injection) stained with TH (red) and gp120 (green) antibodies. $\boldsymbol{b}$, Higher magnification of the boxed area in $\boldsymbol{a}$. Yellow is green plus red. $\boldsymbol{c}, \boldsymbol{d}$, Representative sections from the somatosensory cortex of animals treated with gp120, stained with neurofilament (red) and gp120 (green) antibodies. $\boldsymbol{d}$, Higher magnification of boxed area in c. gp120-IR is present mainly in neurofilament-positive cells in layer V. Yellow is green plus red). Scale bars: $\boldsymbol{a}, 60 \mu \mathrm{m} ; \boldsymbol{b}, 50 \mu \mathrm{m} ; \boldsymbol{c}, 100 \mu \mathrm{m} ; \boldsymbol{d}, 30 \mu \mathrm{m}$. $\boldsymbol{e}$, Time course analysis of gp120 accumulation in the SN and cerebral cortex. Rats received gp120 into the striatum and were killed at 1, 2, 4, 7, and $15 \mathrm{~d}$ after the injection. Analysis of gp120-IR was performed in the indicated areas in a total of 15 sections per animal (8 rats each time point), one every $100 \mu \mathrm{m}$. Data are the mean \pm SEM.

tively internalized by axonal terminals and retrogradely transported to neuronal cell bodies.

\section{gp120-positive neurons exhibit apoptosis}

To examine whether retrogradely transported gp120 induces apoptosis, gp120 or VEH was delivered in the hippocampus or the striatum, and animals were killed $4 \mathrm{~d}$ later. Brains were removed to obtain sections that include the entire SN, septum, and hippocampus. Sections were stained for gp 120 and cleaved caspase- 3 or gp120 followed by TUNEL to confirm apoptosis. By $4 \mathrm{~d}$, several gp120- and caspase-3-positive cells were seen in the SN (Fig. $5 a, d)$ and in the septum (Fig. $5 d$ ). Moreover, gp120 elicited a time-dependent increase in apoptotic neurons (Fig. $5 c, d$ ) that 

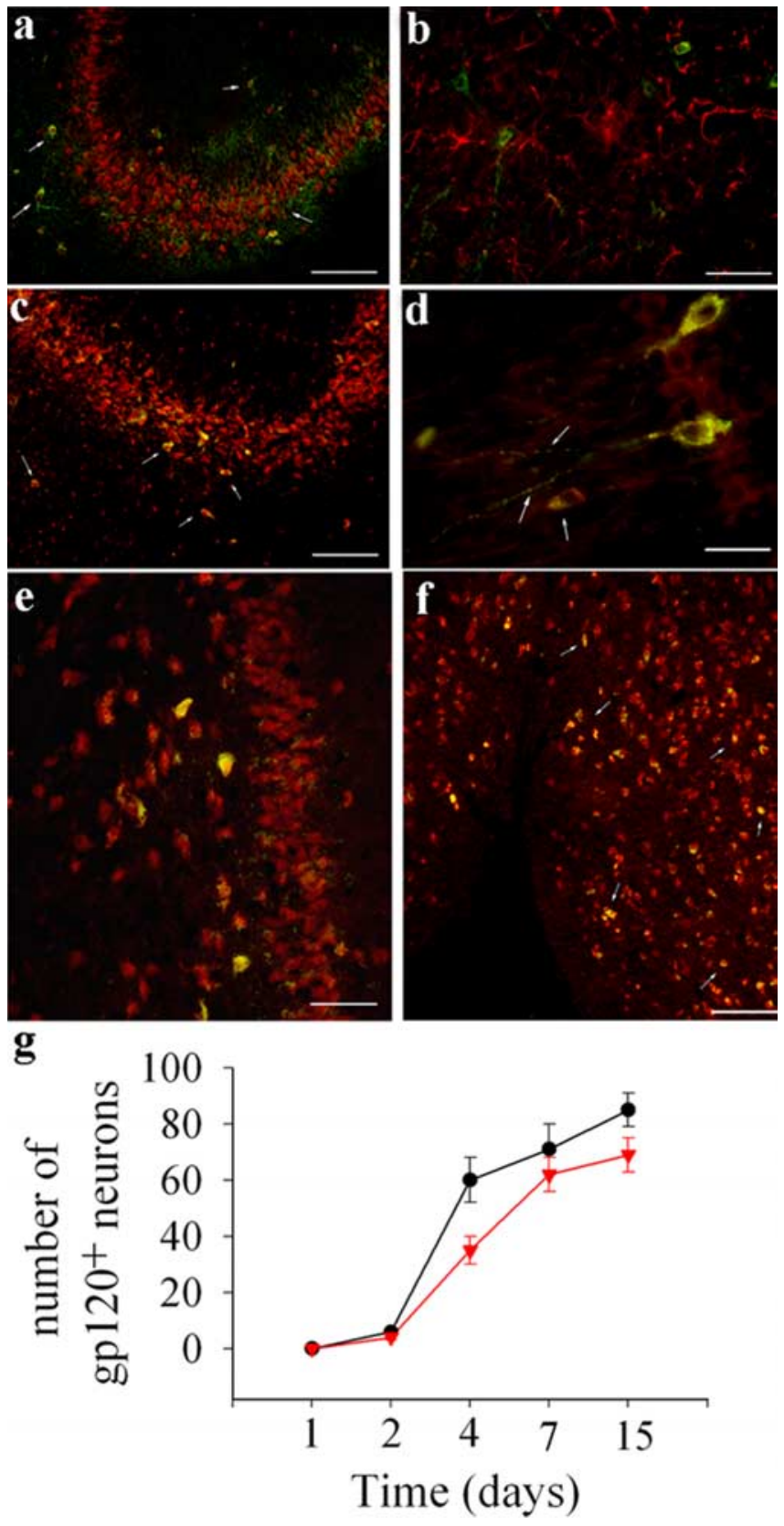

Figure 4. Hippocampal gp120 is retrogradely transported to distal neurons. Rats received gp120 (400 ng) into the dorsal hippocampus or fimbria and were killed 1, 2, 4, 7, and $15 \mathrm{~d}$ later. $\boldsymbol{a}-\boldsymbol{c}$, Sections throughout the ipsilateral hippocampus of gp 120-treated rats (killed $1 \mathrm{~d}$ after the injection into the hippocampus), contralateral hippocampus (d) ( $4 \mathrm{~d}$ after the injection), medial septum $(\boldsymbol{e})$, and diagonal band of Broca $(\boldsymbol{f})(4 \mathrm{~d}$ after the injection into the fimbria), were stained for gp120 (green), NeuN (red, $\boldsymbol{a}, \boldsymbol{e}, \boldsymbol{f}$ ), GFAP (red, $\boldsymbol{b}$ ), MAP2 (red, $\boldsymbol{d}$ ), and CXCR4 (red, $\boldsymbol{c}$ ). Yellow is red plus green. Scale bars: $\boldsymbol{a}, \boldsymbol{c}, \boldsymbol{f}, 125 \mu \mathrm{m} ; \boldsymbol{b}, \boldsymbol{d}, \boldsymbol{e}, 100 \mu \mathrm{m} . \boldsymbol{g}$, gp120-positive neurons were quantified in the septum and contralateral hippocampus at the indicated days after the injection. Data, expressed as the mean \pm SEM of eight animals (13 and 16 sections through the septum and hippocampus each, respectively, 1 every $100 \mu \mathrm{m}$, per animal), represent the average number of cells per section.

correlated with the temporal profile of gp 120 accumulation in cell bodies and processes (Fig. $4 g$ ). In fact, colocalization of gp 120 and TUNEL (Fig. $5 c$ ) or caspase-3 (Fig. $5 d$ ) was seen in more neurons by $7 \mathrm{~d}$ and up to $15 \mathrm{~d}$. By $7 \mathrm{~d}$ in the contralateral hippocampus, both cell bodies and processes (Fig. $5 b$, arrows) exhibited caspase-3-IR. Thus, our data indicate that gp120 accumulation inside neurons and apoptosis are two related phenomena.

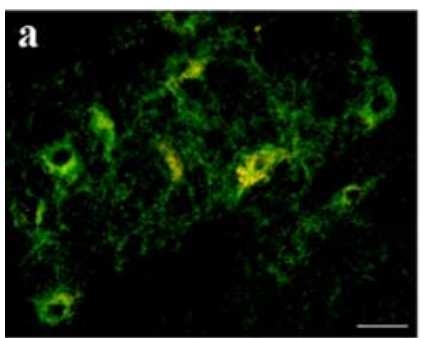

c

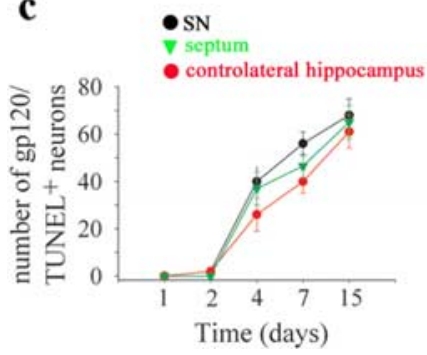

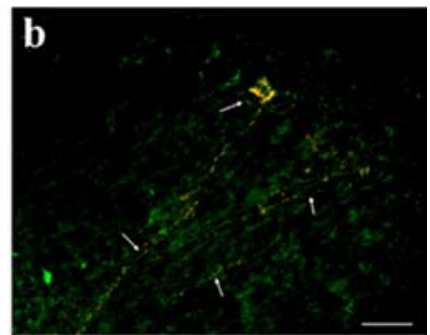

d

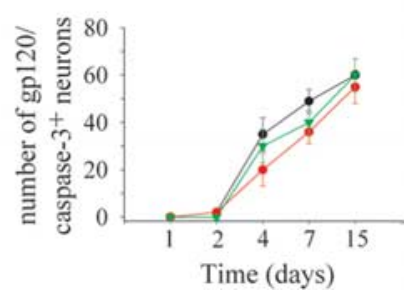

Figure 5. Neurons transporting gp120 are TUNEL and caspase-3 positive. Rats received gp120 (400 ng) into the striatum or hippocampus and were killed at 1,2,4,7, and $15 \mathrm{~d}$ after the injection. Representative sections from the SN (a) or contralateral hippocampus $(\boldsymbol{b})$ taken from animals $7 \mathrm{~d}$ after the injection, stained with cleaved caspase-3 (red) and gp120 (green) antibodies. $\boldsymbol{a}$ and $\boldsymbol{b}$ show that gp 120-positive neurons in the $\mathrm{SN}$ and contralateral hippocampus are also caspase-3 positive. Scale bars: $\boldsymbol{a}, 30 \mu \mathrm{m} ; \boldsymbol{b}, 50 \mu \mathrm{m}$. c, $\boldsymbol{d}$, Time course analysis of gp120-IR colocalization in TUNEL- or caspase-3-positive cells, respectively, in the indicated regions. Data represent the mean \pm SEM of eight rats per group (at least 10 sections each area, each animal).

gp120-mediated apoptosis in distal areas is blocked by colchicine

One approach to study the role of axonal transport in gp120mediated toxicity is to block gp120 transport and examine cell death in distal areas. To block neuronal transport, we selected colchicine, a blocker of all axonal transport that does not alter basal neuronal activity. Moreover, this microtubule-disrupting agent inhibits cellular processes that require an intact and functional microtubule network. Rats received VEH or gp120 (400 $\mathrm{ng})$ in the striatum, alone or in combination with colchicine (10 $\mu \mathrm{M})$. To evade colchicine toxicity, animals were killed $3 \mathrm{~d}$ after the injection. Brain sections throughout the striatum and SN were examined for gp120- and caspase-3-IR as well as for markers of different cellular phenotypes. Control and colchicine-treated animals receiving VEH exhibited a similar number of caspase-3positive cells in the SN (Fig. $6 d$ ), indicating that this dose of colchicines does not cause neuronal damage per se. However, colchicine inhibited retrograde transport and accumulation of gp120 in TH-positive neurons (Fig. $6 a-c$ ), as well as the ability of the glycoprotein to activate neuronal caspase- 3 in the SN (Fig. $6 d$ ). In the striatum, colchicine did not prevent gp120 internalization (Fig. 6e) or gp120-mediated apoptosis (Fig. 6f), supporting the hypothesis that gp120 axonal transport is crucial for neuronal damage only at a distal site. To further prove this hypothesis, AMD3100 (1 $\mu \mathrm{M})$, a CXCR4 antagonist (Donzella et al., 1998), and gp120 were injected into the striatum, and gp120-IR and apoptosis were analyzed in the SN. AMD3100 inhibited both gp120 accumulation (Fig. 7a) and apoptosis of dopaminergic neurons (Fig. 7b), supporting the role of CXCR4 in gp120 internalization and apoptosis.

Time-dependent internalization of gp120

A great proportion of cultured rat CGCs internalize gp120 (Bachis et al., 2003). These neurons undergo apoptotic cells death during exposure to gp120 in a CXCR4-dependent manner 


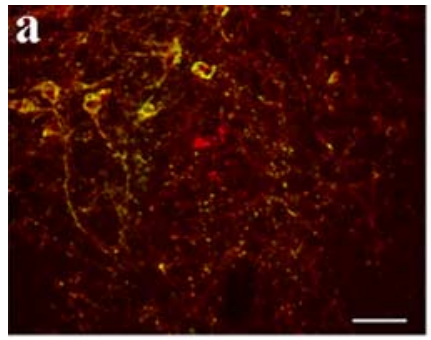

C
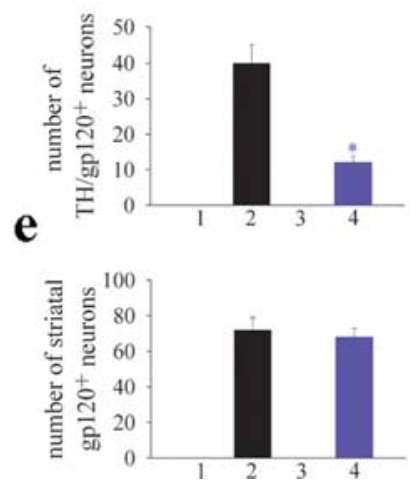

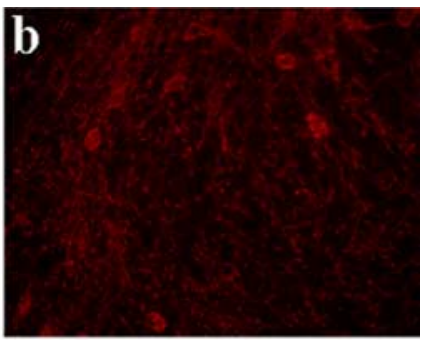

d
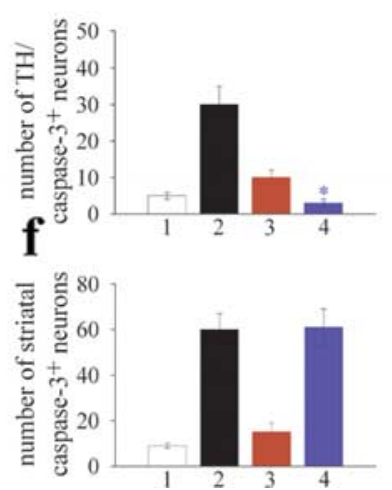

Figure 6. Colchicine blocks gp120 retrograde transport and apoptosis. Rats received VEH (1), gp120 (2), colchicine (3), or colchicine plus gp120 (4) into the striatum and were killed $3 \mathrm{~d}$ later. Representative sections from the SN of rats treated with gp120(a) or gp120 plus colchicine (b) showing colocalization of gp120-IR (green) in TH (red)-positive neurons. Note that colocalization occurs only in $\boldsymbol{a}$. Scale bar, $50 \mu \mathrm{m}$. Semiquantitative analysis of TH- and gp120-positive neurons $(\boldsymbol{c})$ and caspase-3- and TH-IR (d) in sections from the SN. Number of gp120-IR neurons $(\boldsymbol{e})$ and caspase-3-positive neurons $(\boldsymbol{f})$ in the striatum. Data, expressed as the mean \pm SEM of four animals per group (at least 10 sections per animal), represent the average number of positive cells per section. ${ }^{*} p<0.001$ versus gp 120 . a

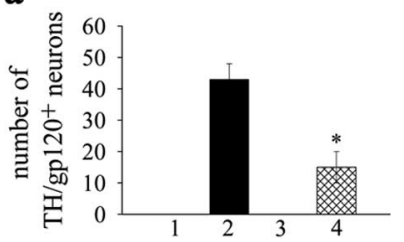

b

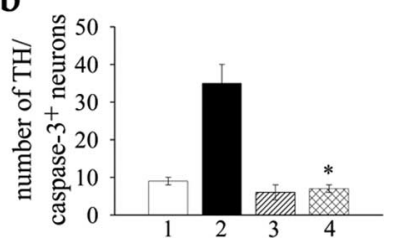

Figure 7. AMD3100 blocks gp120-mediated activation of caspase- 3 in the SN. Rats received VEH (1), gp120 (2), AMD3100 (3), or AMD3100 plus gp120 (4) into the striatum and were killed $4 \mathrm{~d}$ later. Semiquantitative analysis of TH/gp120 (a) and TH/caspase-3-positive neurons (b) in the SN. Data, expressed as the mean \pm SEM of four animals per group (at least 10 sections per animal), represent the average number of positive cells per section. ${ }^{*} p<0.001$ versus gp120.

(Bachis et al., 2003). To examine retrograde transport and subcellular compartmentalization of gp120, CGCs were exposed to 5 nM gp120 conjugated to colloidal gold for 5, 15, 30, and $60 \mathrm{~min}$. Cells were then fixed and processed for electron microscopy. At 5 $\mathrm{min}$, the majority of gold particles were localized around synaptic terminals (Fig. 8A). By 15 min, several gold particles were observed inside synaptic terminals surrounded by synaptic vesicles (Fig. $8 \mathrm{~B}$ ). At 15 and $30 \mathrm{~min}$, gold particles were observed on microtubules (Fig. $8 C$ ), suggesting axonal transport. By $1 \mathrm{~h}$, the majority of particles were inside lysosomes (Fig. 8D). This is consistent with their role in recycling and intracellular digestion of glycoproteins. Overall, these data support the hypothesis that gp120 is internalized and transported to the cell body (Bachis et al., 2003).
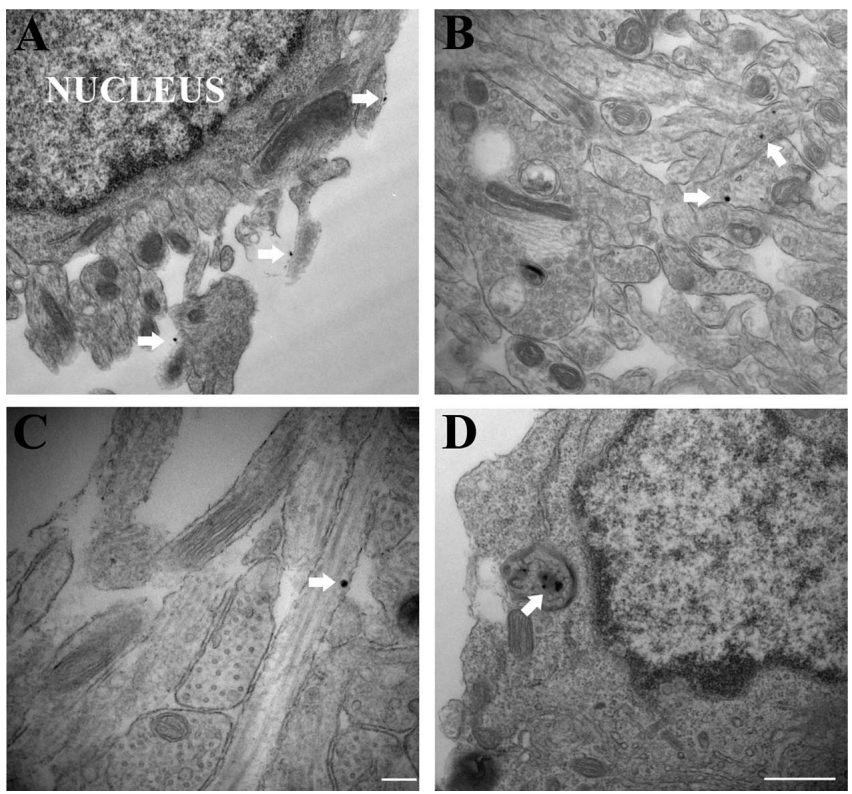

Figure 8. Subcellular localization of gold-labeled gp120 in cerebellar granule cells. Representative electron microscopic images of CGCs taken at $5(\boldsymbol{A}), 15(\boldsymbol{B}), 30(\boldsymbol{C})$, and $60(\boldsymbol{D})$ min after gp120 incubation. The gold-labeled gp120 (arrows) is first seen attached to apparent receptor sites outside synaptic endings $(\boldsymbol{A})$ and after internalization into synaptic terminals $(\boldsymbol{B})$. At 30 $\min (\boldsymbol{C})$, the gold-labeled gp120 can be seen in association with microtubules within neuronal processes and at $60 \mathrm{~min}(\boldsymbol{D})$ within lysosomes in the cell body. Scale bars: $\boldsymbol{A}, \boldsymbol{B}, \boldsymbol{D}, 500 \mathrm{~nm}$; C, $200 \mathrm{~nm}$.

\section{gp120 neurotoxicity and microtubules}

The role of microtubules in gp120 retrograde axonal transport was further tested in CGCs. Neurons were exposed to gp120 (5 $\mathrm{nM}$ ) for $30 \mathrm{~min}$ and $6 \mathrm{~h}$ alone or in combination with nocodazole $(5 \mu \mathrm{g} / \mathrm{ml})$, an agent that depolymerizes the microtubule network (Cid-Arregui et al., 1995). By $30 \mathrm{~min}$, in gp120-treated cells without nocodazole, gp120-IR was localized both in the soma and processes (Fig. 9a). By 6 h, gp120-treated neurons exhibited retraction of processes (Fig. 9c). In nocodazole-treated CGCs, gp120-IR was mostly distributed in the soma at both time points (Fig. 9b,d), suggesting that nocodazole does not block gp120 internalization but inhibits its axonal transport. Moreover, nocodazole inhibited the ability of gp120 to induce retraction of processes (Fig. 9).

To further confirm the importance of axonal transport in gp120-mediated cell death, CGCs were exposed to nocodazole alone or in combination with gp120. The number of caspase-3positive neurons was then measured $30 \mathrm{~min}$ and $6 \mathrm{~h}$ after gp 120 treatment. Cleaved caspase-3-IR was seen in a very small number of CGCs exposed to gp120 for $30 \mathrm{~min}$ (Fig. 9e). By 6 h, 40\% of neurons treated with gp120 alone were casapse- 3 immunoreactive. Nocodazole, which has very little effect on caspase- 3 activation after $6 \mathrm{~h}$ per se, prevented gp120-mediated apoptosis (Fig. $9 e$ ). These data strengthen the hypothesis that axonal transport of gp120 is crucial for its toxic effect.

\section{Discussion}

Productive HIV-1 infection does not occur in neurons; rather, it is confined to macrophages and related microglia (Lee et al., 1993; Persidsky and Gendelman, 2003). Nonetheless, one of the characteristics of ADC is neuronal loss. This apparent discrepancy has led to the consensus that HIV-1 viral proteins, including gp120, contribute to the neuronal dysfunction in ADC patients (Kaul et al., 2001). However, the issue of whether gp120 is neu- 

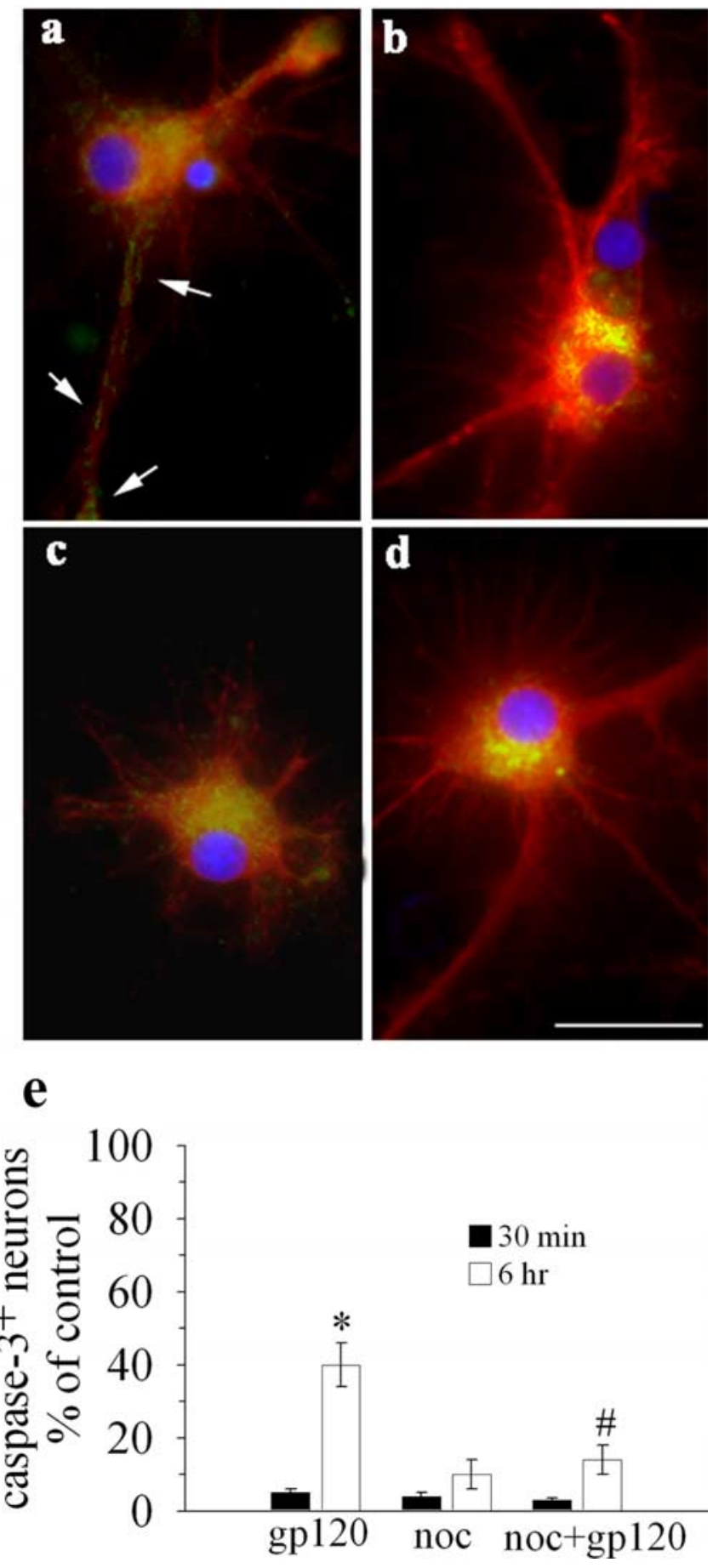

Figure 9. Nocodazole blocks gp120-mediated axonal transport and retraction. CGCs were exposed to gp120 ( $5 \mathrm{~nm})$ for $30 \mathrm{~min}(\boldsymbol{a})$, nocodazole $(5 \mu \mathrm{g} / \mathrm{ml})$ plus gp120 for $30 \mathrm{~min}(\boldsymbol{b})$, gp120 for $6 \mathrm{~h}(\boldsymbol{c})$, or nocodazole plus gp120 for $6 \mathrm{~h}(\boldsymbol{d})$. Nocodazole was added to the cultures $15 \mathrm{~min}$ before gp120. Neurons were fixed and stained for gp120 (green), DAPI (blue), or MAP2 (red). Note in $\boldsymbol{a}$ gp120-IR in neuronal processes (arrows). Scale bar, $20 \mu \mathrm{m} . \boldsymbol{e}$, Caspase-3-positive neurons were determined $30 \mathrm{~min}$ and $6 \mathrm{~h}$ after gp120 and nocodozole (noc) alone or in combination. Values are the mean \pm SEM $(n=8) .{ }^{*} p<0.001$ versus control; ${ }^{*} p<0.005$ versus gp120.

rotoxic by interacting directly with neurons or by inducing the release of endogenous soluble toxins is still contentious. Our discovery that gp120IIIB is internalized by neurons expressing CXCR4 and then transported to the soma before inducing apoptosis adds a new theory for the pathogenesis of HIV-1 T-tropic strains. Combined with previous data showing widespread neuronal apoptosis after injection of gp120IIIB into the rat lateral ventricle (Acquas et al., 2004), these findings indicate that, in the late phase of infection, T-tropic gp120 strains or other viral proteins released from HIV or infected microglia can induce apoptosis by directly interacting with neuronal receptors. gp120, in turn, is internalized by neurons and activates caspase- 3 or accumulates in cell bodies of distal neurons, in which it activates proapoptotic signal transduction cascades. The latter appears to require axonal transport. Thus, we provide the new hypothesis that CXCR4mediated gp120 neuronal endocytosis and trafficking may contribute to neuronal loss observed in ADC (James et al., 1999; Petito et al., 1999; Garden et al., 2002). It remains to be established whether axonal transport may also be involved in the neurotoxic property of M-tropic strains of gp120 (e.g., BaL), which predominate in the early phase of infection and use CCR5 as a coreceptor (rev in Gonzalez-Scarano and Martin-Garcia, 2005). However, it is important to note that CCR5-using gp120 may have a different neurotoxic mechanism because the M-tropic gp120BaL is less neurotoxic than gp120IIIB in vitro (Bachis and Mocchetti, 2005) and RANTES (regulated on activation normal T-cell expressed and secreted), the natural ligand of CCR5, is neuroprotective against gp120 (Meucci et al., 1998; Kaul and Lipton, 1999; Bachis and Mocchetti, 2005).

Our results support a model of HIV-1 neurotoxicity in which HIV proteins are taken up by neuronal membranes and transported to the soma in a biologically active form (Liu et al., 2000; Bruce-Keller et al., 2003). In fact, colchicine, a microtubuledisrupting agent that inhibits cellular processes that require an intact and functional microtubule network, significantly reduced gp120 transport and accumulation in distal areas. Likewise, colchicine prevented the gp120-mediated activation of caspase-3, indicating that trafficking of gp120 along the axon is crucial to its neurotoxic effect in distal neurons. Nevertheless, caspase-3positive neurons were observed at the site of injection despite colchicine treatment. Therefore, we cannot exclude that gp120 may activate an apoptotic pathway after being internalized but before being axonally transported. Conversely, colchicine was administered concomitantly to gp120 to avoid its intrinsic toxicity. This may indicate that neuronal protection against gp120 at the injection site could be achieved only if colchicine is administered before gp120. To further test our hypothesis, we investigated gp120 axonal transport in CGCs using colchicine or nocodazole, another cytoskeletal transport disrupting agent before gp120. Both colchicine (data not shown) and nocodazole blocked gp120-mediated apoptosis, supporting our hypothesis that axonal transport is involved in the toxic effect of gp 120.

CXCR4 appears to be the chief molecular mediator of the membrane-associated endocytosis of gp120 because the CXCR4 antagonist AMD3100 blocked both gp120 internalization and its neurotoxic effect. Once gp120 is internalized, its transport along the axon may occur as a ligand-receptor complex, as has been demonstrated for other G-protein-coupled receptors (Claing et al., 2002). Indeed, CXCR4 undergoes internalization during exposure to SDF via an arrestin-mediated pathway in non-neuronal cells (Orsini et al., 2000). Alternatively, gp120 transport may occur in a CXCR4-independent manner and may involve lowdensity lipoprotein-receptor-related proteins, which have been shown to translocate HIV-1 transactivator protein to neuronal nuclei (Liu et al., 2000). Future studies will characterize in more detail the cellular mechanism(s) of gp120 axonal transport.

gp120IIIB uptake and accumulation in axons is reminiscent of a "suicide transport" observed for other glycoproteins, such as 
the cellular prion protein (Borchelt et al., 1994), or viral proteins, such as the tegument proteins of the herpes virus (Bearer et al., 2000). However, unlike the prion glycoprotein, gp120 is not expressed by neurons because HIV-1 replication occurs mainly in non-neuronal cells such as microglia and macrophages. The retrograde transport of herpes virus occurs mainly in the peripheral nervous system and appears to require fusion with the membrane. gp120 axonal transport and apoptosis instead take place in various CXCR4-expressing neuronal populations, including dopaminergic neurons of the $\mathrm{SN}$, neocortical neurons in layer $\mathrm{V}$, hippocampal pyramidal and granule neurons, and septal neurons. The entry of gp120 in these neurons is consistent with a receptor-mediated mechanism because AMD3100 inhibited both gp120 internalization and neurotoxicity, suggesting that gp120IIIB uses the host-endocytic machinery of CXCR4 to enter neurons. Interestingly, gp 120 was not internalized by astrocytes, which are known to clear various byproducts and neurotransmitters through active uptake (Nedergaard et al., 2003). Moreover, we did not observe apoptosis in astrocytes. However, astrocytes express CXCR4, are sensitive to gp120 (Toggas et al., 1994; Bezzi et al., 2001), and can support limited viral CD4-independent infection and replication (Tornatore et al., 1994; KramerHammerle et al., 2005). Therefore, it appears that CXCR4 binding without internalization may not be sufficient to induce cell damage. gp120 transgenic mice exhibit widespread neuronal apoptosis, reactive astrocytosis, and an increased number of microglia cells, which is reminiscent of the earliest changes found in ADC patients (Toggas et al., 1994). In this and previous studies (Nosheny et al., 2004), we did not observe alterations in the number of glial cells, and neuronal apoptosis was confined to a portion of the striatum, $\mathrm{SN}$, and basal forebrain. However, these data do not conflict with those of Toggas et al. (1994) because neurodegeneration in our rodent model is obtained with a single injection of gp120 in discrete regions of the brain, whereas transgenic mice are continuously exposed to gp120 for a prolonged time. Conversely, astroglial alterations observed in transgenic mice could be induced by signals from damaged neurons. Therefore, it may represent a secondary response to the initial insult caused by gp120. Intriguingly, we observed retrograde degeneration of nigrostriatal fibers and retraction of neuronal processes in CGCs treated with gp120, which is consistent with a decrease in synaptodendritic complexity observed in brains of gp120 transgenic mice (Toggas et al., 1994). Therefore, despite the fact that a single gp120 injection does not produce astroglial alterations, this experimental model produces early signs of neuronal damage seen in ADC.

How internalized and axonally transported gp 120 causes neuronal apoptosis is still under investigation. Neurons depend on axons and dendrites, which mediate communication between distant cells. These far-reaching processes require extensive intracellular transport, which is primarily mediated by cytoskeletal filaments, including microtubules (Lee et al., 2003). Electron microscopy studies have revealed that, after endocytosis, gp120-IR associates with microtubules. By preventing cytoskeletal transport of gp120 with colchicine or nocodazole, gp120 loses its neurotoxic activity on distal neurons despite the fact that internalization is not prevented. Because in macrophages and other cell types gp120 activates cytoskeleton-associated protein kinases such as the focal adhesion-related kinases Pyk2 and FAK (Avraham et al., 2000), we hypothesize that gp120 induces neuronal degeneration by disrupting axonal cytoskeleton. Conversely, we observed accumulation of gp120 inside lysosomes. When lysosomes cannot recycle/degrade efficiently, an excess storage of var- ious molecules within the cells is created. This abnormal accumulation of undigested material within neurons can lead to cell death (Zhang et al., 2001). In particular, there is evidence that abnormal ceramide metabolism in relation to aberrant lysosomal function can cause neurodegenerative diseases (DitarantoDesimone et al., 2003). ADC patients have high levels of ceramide (Haughey et al., 2004), and gp120 increases ceramide levels in cultured cells (Haughey et al., 2004). Thus, gp120 may kill neurons by entering lysosomes and disrupting the metabolism of sphingolipids. Future experiments will test these hypotheses.

The goal of the present report was to reveal potentially new cellular and molecular mechanisms causing ADC. We reproduced neuronal apoptosis seen in ADC by using gp120IIIB, and we postulated a theory of how T-tropic HIV-1 can cause neuronal injury at a distance. Our experimental model, however, poses some limitations if extrapolated to the human situation. ADC occurs late during the course of systemic infection when neurons have been exposed to HIV-1 for many years. The evidence obtained in this report is derived from an acute toxic effect of gp 120. Acute injection of gp120 in rat brain does not elicit a robust inflammatory effect (Nosheny et al., 2004), which is believed to participate in the neurotoxic effect of HIV-1 (Albright et al., 2003). Indeed, infection of perivascular macrophages and microglia can produce neuronal damage by releasing inflammatory cytokines or chemokines (for review, see Gonzalez-Scarano and Martin-Garcia, 2005). However, our data do not exclude the theory of an indirect mechanism because gp120 by damaging neurons may trigger a cascade of inflammatory processes that then lead to widespread neuronal damage. Finally, apoptotic signals induced by gp120IIIB may render neurons more sensitive to CCR5-using strains or activate metalloproteinase to cleave SDF, which is known to be 10 -fold more toxic to neurons than the uncleaved form (Zhang et al., 2003). Thus, in the clinical situation, a variety of indirect and direct mechanisms may contribute to the neurotoxicity associated with ADC. The data presented here demonstrating a direct neurotoxic mechanisms of gp120IIIB help elucidating the dynamic interplay between host neurons and viral proteins in ADC.

\section{References}

Acquas E, Bachis A, Nosheny RL, Cernak I, Mocchetti I (2004) Human immunodeficiency virus type 1 protein gp120 causes neuronal cell death in the rat brain by activating caspases. Neurotox Res 5:605-615.

Albright AV, Shieh JT, Itoh T, Lee B, Pleasure D, O'Connor MJ, Doms RW, Gonzalez-Scarano F (1999) Microglia express CCR5, CXCR4, and CCR3, but of these, CCR5 is the principal coreceptor for human immunodeficiency virus type 1 dementia isolates. J Virol 73:205-213.

Albright AV, Soldan SS, Gonzalez-Scarano F (2003) Pathogenesis of human immunodeficiency virus-induced neurological disease. J Neurovirol 9:222-227.

Avraham H, Park S-Y, Schinkmann K, Avraham S (2000) RAFTK/Pyk2mediated cellular signalling. Cell Signal 12:123-133.

Bachis A, Mocchetti I (2004) The chemokine receptor CXCR4 and not the $N$-methyl-D-aspartate receptor mediates gp 120 neurotoxicity in cerebellar granule cells. J Neurosci Res 75:75-82.

Bachis A, Mocchetti I (2005) Brain-derived neurotrophic factor is neuroprotective against human immunodeficiency virus-1 envelope proteins. Ann NY Acad Sci 1053:247-257.

Bachis A, Major EO, Mocchetti I (2003) Brain-derived neurotrophic factor inhibits human immunodeficiency virus-1/gp120-mediated cerebellar granule cell death by preventing gp120 internalization. J Neurosci 23:5715-5722.

Bagetta G, Corasaniti MT, Aloe L, Berliocchi L, Costa N, Finazzi-Agro A, Nistico G (1996) Intracerebral injection of human immunodeficiency virus type 1 coat protein gp120 differentially affects the expression of nerve growth factor and nitric oxide synthase in the hippocampus of rat. Proc Natl Acad Sci USA 93:928-933. 
Bagri A, Gurney T, He X, Zou YR, Littman DR, Tessier-Lavigne M, Pleasure SJ (2002) The chemokine SDF1 regulates migration of dentate granule cells. Development 129:4249-4260.

Bansal AK, Mactutus CF, Nath A, Maragos W, Hauser KF, Booze RM (2000) Neurotoxicity of HIV-1 proteins gp120 and Tat in the rat striatum. Brain Res 879:42-49.

Bearer EL, Breakefield XO, Schuback D, Reese TS, LaVail JH (2000) Retrograde axonal transport of herpes simplex virus: evidence for a single mechanism and a role for tegument. Proc Natl Acad Sci USA 97:8146-8150.

Berger EA, Murphy PM, Farber JM (1999) Chemokine receptors as HIV-1 coreceptors: roles in viral entry, tropism, and disease. Annu Rev Immunol 17:657-700

Bezzi P, Domercq M, Brambilla L, Galli R, Schols D, De Clercq E, Vescovi A, Bagetta G, Kollias G, Meldolesi J, Volterra A (2001) CXCR4-activated astrocyte glutamate release via TNFalpha: amplification by microglia triggers neurotoxicity. Nat Neurosci 4:702-710.

Biard-Piechaczyk M, Robert-Hebmann V, Richard V, Roland J, Hipskind RA, Devaux C (2000) Caspase-dependent apoptosis of cells expressing the chemokine receptor CXCR4 is induced by cell membrane-associated human immunodeficiency virus type 1 envelope glycoprotein (gp120). Virology 268:329-344.

Borchelt DR, Koliatsos VE, Guarnieri M, Pardo CA, Sisodia SS, Price DL (1994) Rapid anterograde axonal transport of the cellular prion glycoprotein in the peripheral and central nervous systems. J Biol Chem 269:14711-14714.

Brandoli C, Sanna A, De Bernardi MA, Follesa P, Brooker G, Mocchetti I (1998) Brain-derived neurotrophic factor and basic fibroblast growth factor downregulate NMDA receptor function in cerebellar granule cells. J Neurosci 18:7953-7961.

Bruce-Keller AJ, Chauhan A, Dimayuga FO, Gee J, Keller JN, Nath (2003) A Synaptic transport of human immunodeficiency virus-Tat protein causes neurotoxicity and gliosis in rat brain. J Neurosci 23:8417-8422.

Cid-Arregui A, Parton RG, Simons K, Dotti CG (1995) Nocodazoledependent transport, and brefeldin A-sensitive processing and sorting, of newly synthesized membrane proteins in cultured neurons. J Neurosci 15:4259-4269.

Claing A, Laporte SA, Caron MG, Lefkowitz RJ (2002) Endocytosis of G protein-coupled receptors: roles of $\mathrm{G}$ protein-coupled receptor kinases and beta-arrestin proteins. Prog Neurobiol 66:61-79.

Deng H, Liu R, Ellmeier W, Choe S, Unutmaz D, Burkhart M, Di Marzio P, Marmon S, Sutton RE, Hill CM, Davis CB, Peiper SC, Schall TJ, Littman DR, Landau NR (1996) Identification of a major co-receptor for primary isolates of HIV-1. Nature 381:661-666.

Ditaranto-Desimone K, Saito M, Tekirian TL, Saito M, Berg M, Dubowchik G, Soreghan B, Thomas S, Marks N, Yang AJ (2003) Neuronal endoso$\mathrm{mal} /$ lysosomal membrane destabilization activates caspases and induces abnormal accumulation of the lipid secondary messenger ceramide. Brain Res Bull 59:523-531.

Donzella GA, Schols D, Lin SW, Este JA, Nagashima KA, Maddon PJ, Allaway GP, Sakmar TP, Henson G, De Clercq E, Moore JP (1998) AMD3100, a small molecule inhibitor of HIV-1 entry via the CXCR4 co-receptor. Nat Med 4:72-77.

Everall IP, Hansen LA, Masliah E (2005) The shifting patterns of HIV encephalitis neuropathology. Neurotox Res 8:51-61.

Garden GA, Budd SL, Tsai E, Hanson L, Kaul M, D’Emilia DM, Friedlander RM, Yuan J, Masliah E, Lipton SA (2002) Caspase cascades in human immunodeficiency virus-associated neurodegeneration. J Neurosci 22:4015-4024.

Ghorpade A, Nukuna A, Che M, Haggerty S, Persidsky Y, Carter E, Carhart L, Shafer L, Gendelman HE (1998) Human immunodeficiency virus neurotropism: an analysis of viral replication and cytopathicity for divergent strains in monocytes and microglia. J Virol 72:3340-3350.

Gonzalez-Scarano F, Martin-Garcia J (2005) The neuropathogenesis of AIDS. Nat Rev Immunol 5:69-81.

Haughey N, Cutler R, Tamara A, McArthur JC, Vargas DL, Pardo CA, Turchan J, Nath A, Mattson MP (2004) Perturbation of sphingolipid metabolism and ceramide production in HIV-dementia. Ann Neurol 55:257-267.

Hesselgesser J, Horuk R (1999) Chemokine and chemokine receptor expression in the central nervous system. J Neurovirol 5:13-26.

Hesselgesser J, Taub D, Baskar P, Greenberg M, Hoxie J, Kolson DL, Horuk R
(1998) Neuronal apoptosis induced by HIV-1 gp120 and the chemokine SDF-1 alpha is mediated by the chemokine receptor CXCR4. Curr Biol 8:595-598.

James HJ, Sharer LR, Zhang Q, Wang HG, Epstein LG, Reed JC, Gelbard HA (1999) Expression of caspase-3 in brains from paediatric patients with HIV-1 encephalitis. Neuropathol Appl Neurobiol 25:380-386.

Kaul M, Lipton SA (1999) Chemokines and activated macrophages in HIV gp120-induced neuronal apoptosis. Proc Natl Acad Sci USA 96:8212-8216.

Kaul M, Garden GA, Lipton SA (2001) Pathways to neuronal injury and apoptosis in HIV-associated dementia. Nature 410:988-994.

Klein RS, Williams KC, Alvarez-Hernandez X, Westmoreland S, Force T, Lackner AA, Luster AD (1999) Chemokine receptor expression and signaling in macaque and human fetal neurons and astrocytes: implications for the neuropathogenesis of AIDS. J Immunol 163:1636-1646.

Klein RS, Rubin JB, Gibson HD, DeHaan EN, Alvarez-Hernandez X, Segal RA, Luster AD (2001) SDF-1 alpha induces chemotaxis and enhances Sonic hedgehog-induced proliferation of cerebellar granule cells. Development 128:1971-1981.

Kramer-Hammerle S, Rothenaigner I, Wolff H, Bell JE, Brack-Werner R (2005) Cells of the central nervous system as targets and reservoirs of the human immunodeficiency virus. Virus Res 111:194-213.

Kure K, Llena JF, Lyman WD, Soeiro R, Weidenheim KM, Hirano A, Dickson DW (1991) Human immunodeficiency virus-1 infection of the nervous system: an autopsy study of 268 adult, pediatric, and fetal brains. Hum Pathol 22:700-710.

Lavi E, Strizki JM, Ulrich AM, Zhang W, Fu L, Wang Q, O'Connor M, Hoxie JA, Gonzalez-Scarano F (1997) CXCR-4 (Fusin), a co-receptor for the type 1 human immunodeficiency virus (HIV-1), is expressed in the human brain in a variety of cell types, including microglia and neurons. Am J Pathol 151:1035-1042.

Lazarini F, Tham TN, Casanova P, Arenzana-Seisdedos F, Dubois-Dalcq M (2003) Role of the alpha-chemokine stromal cell-derived factor (SDF-1) in the developing and mature central nervous system. Glia 42:139-148.

Lee C, Liu Q-H, Tomkowicz B, Yi Y, Freedman BD, Collman RG (2003) Macrophage activation through CCR5- and CXCR4-mediated gp120elicited signaling pathways. J Leukoc Biol 74:676-682.

Lee SC, Hatch WC, Liu W, Kress Y, Lyman WD, Dickson DW (1993) Productive infection of human fetal microglia by HIV-1. Am J Pathol 143:1032-1039.

Liu Y, Jones M, Hingtgen CM, Bu G, Laribee N, Tanzi RE, Moir RD, Nath A, He JJ (2000) Uptake of HIV-1 tat protein mediated by low-density lipoprotein receptor-related protein disrupts the neuronal metabolic balance of the receptor ligands. Nat Med 6:1380-1387.

Ma Q, Jones D, Borghesani PR, Segal RA, Nagasawa T, Kishimoto T, Bronson RT, Springer TA (1998) Impaired B-lymphopoiesis, myelopoiesis, and derailed cerebellar neuron migration in CXCR4- and SDF-1-deficient mice. Proc Natl Acad Sci USA 95:9448-9453.

Maccarrone M, Bari M, Corasaniti MT, Nistico R, Bagetta G, Finazzi-Agro A (2000) HIV-1 coat glycoprotein gp120 induces apoptosis in rat brain neocortex by deranging the arachidonate cascade in favor of prostanoids J Neurochem 75:196-203.

Masliah E, Heaton RK, Marcotte TD, Ellis RJ, Wiley CA, Mallory M, Achim CL, McCutchan JA, Nelson JA, Atkinson JH, Grant I (1997) Dendritic injury is a pathological substrate for human immunodeficiency virusrelated cognitive disorders. HNRC Group. The HIV Neurobehavioral Research Center. Ann Neurol 42:963-972.

Meucci O, Fatatis A, Simen AA, Bushell TJ, Gray PW, Miller RJ (1998) Chemokines regulate hippocampal neuronal signaling and gp120 neurotoxicity. Proc Natl Acad Sci USA 95:14500-14505.

Nedergaard M, Ransom B, Goldman SA (2003) New roles for astrocytes: redefining the functional architecture of the brain. Trends Neurosci 26:523-530.

Nosheny RL, Bachis A, Acquas E, Mocchetti I (2004) Human immunodeficiency virus type 1 glycoprotein gp 120 reduces the levels of brain-derived neurotrophic factor in vivo: potential implication for neuronal cell death. Eur J Neurosci 20:2857-2864.

Orsini MJ, Parent JL, Mundell SJ, Marchese A, Benovic JL (2000) Trafficking of the HIV coreceptor CXCR4: role of arrestins and identification of residues in the $\mathrm{C}$-terminal tail that mediate receptor internalization. J Biol Chem 275:25876. 
Paxinos G, Watson C (1998) The rat brain in stereotaxic coordinates. San Diego: Academic.

Persidsky Y, Gendelman HE (2003) Mononuclear phagocyte immunity and the neuropathogenesis of HIV-1 infection. J Leukoc Biol 74:691-701.

Petito CK, Kerza-Kwiatecki AP, Gendelman HE, McCarthy M, Nath A, Podack ER, Shapshak P, Wiley CA (1999) Review: neuronal injury in HIV infection. J Neurovirol 5:327-341.

Price RW (1996) Neurological complications of HIV infection. Lancet 348:445-452.

Rossi D, Zlotnik A (2000) The biology of chemokines and their receptors. Annu Rev Immunol 18:217-242.

Stumm RK, Rummel J, Junker V, Culmsee C, Pfeiffer M, Krieglstein J, Hollt $\mathrm{V}$, Schulz S (2002) A dual role for the SDF-1/CXCR4 chemokine receptor system in adult brain: isoform-selective regulation of SDF-1 expression modulates CXCR4-dependent neuronal plasticity and cerebral leukocyte recruitment after focal ischemia. J Neurosci 22:5865-5878.

Tarasova NI, Stauber RH, Michejda CJ (1998) Spontaneous and ligandinduced trafficking of CXC-chemokine receptor 4. J Biol Chem 273:15883-15886.

Toggas SM, Masliah E, Rockenstein EM, Rall GF, Abraham CR, Mucke L (1994) Central nervous system damage produced by expression of the HIV-1 coat protein gp120 in transgenic mice. Nature 367:188-193.

Tornatore C, Chandra R, Berger JR, Major EO (1994) HIV-1 infection of subcortical astrocytes in the pediatric central nervous system. Neurology 44:481-487.

van der Meer P, Ulrich AM, Gonzalez-Scarano F, Lavi E (2000) Immunohistochemical analysis of CCR2, CCR3, CCR5, and CXCR4 in the human brain: potential mechanisms for HIV dementia. Exp Mol Pathol 69:192-201.

Zhang K, McQuibban GA, Silva C, Butler GS, Johnston JB, Holden J, ClarkLewis I, Overall CM, Power C (2003) HIV-induced metalloproteinase processing of the chemokine stromal cell derived factor-1 causes neurodegeneration. Nat Neurosci 6:1064-1071.

Zhang Z, Butler JD, Levin SW, Wisniewski KE, Brooks SS, Mukherjee AB (2001) Lysosomal ceroid depletion by drugs: therapeutic implications for a hereditary neurodegenerative disease of childhood. Nat Med 7:478-484

Zheng J, Thylin MR, Ghorpade A, Xiong H, Persidsky Y, Cotter R, Niemann D, Che M, Zeng YC, Gelbard HA, Shepard RB, Swartz JM, Gendelman HE (1999) Intracellular CXCR4 signaling, neuronal apoptosis and neuropathogenic mechanisms of HIV-1-associated dementia. J Neuroimmunol 98:185-200.

Zou YR, Kottmann AH, Kuroda M, Taniuchi I, Littman DR (1998) Function of the chemokine receptor CXCR4 in haematopoiesis and in cerebellar development. Nature 393:595-599. 